\title{
Teacher: An Important but Less Recognized Actor of School Curriculum Development in Nepal
}

Kalpana Rimal

\begin{abstract}
Curriculum development is considered as a key factor in the process of educational transformation. In this process, teachers can play multiple roles such as translator of learning objectives into outcome, mediator between curriculum and students and so on. On the other hand, curriculum experts contribute to making a need assessment and contents development on the basis of educational theories and principles. But, contemporary literatures point gaps in exchange of knowledge and expertise between these two important actors of school curriculum development. On this backdrop, this study aims to explore what rolesteachers can perform and how their rolesare acknowledged in the curriculum development. Following social constructivist worldview, this study adopted qualitative approach with the scientific tool of in-depth interviewsand purposive sampling design. This study reveals teacher's contribution inidentification of practical educational needsin the context of changing overall societal needs.Moreover, the teacherscan bridge existing gaps between national educational goals, social needs and the interest of people. But the current school curriculum development process takes place at the top where curriculum experts play decisive role. These experts seek school teacher's contribution only at the review phase of curriculum development process which is not enough to incorporate teacher's expertise. In this respect, teachers will be able to view curriculum not in terms of content to be covered, but as a transformative process. Rather, this looks like just maintaining a formality. The attitudinal and procedural process constrain in recognition and involvement of teacher in curriculum development process. Thus, school curriculum has missed opportunity to reflect local need and increase ownership of the teachers. This paper argues for the recognition of teacher's role as a critical practitioner and change agent, and urges to provide sufficient space to incorporate their real-life experiences in school curriculum.
\end{abstract}

Keywords: school education, curriculum development, teacher's role, experts

\section{Introduction}

Curriculum refers to a course of study at a school or university that directly offers the guidelines on formal education. According to De Coninck (2008), curriculum is now considered as one of the centres of daily life and the responsibility of society. Like De Coninck, different scholars have introduced curriculum in their own word such as curriculum as praxis, run way, roadmap, guideline, plan for instruction, blueprint for what is going to be taught and so on. Brown, Ryan and Creswell (2007) maintain that a curriculum includes students' school experiences related to their skills and strategies which is essential to improve critical thinking and creativity, problem solving skill, collaborative work, communication, effective writing, reading and conducting research. Actually curriculum needs to be defined as dealing with the experience of the learner. Similarly, Tyler (1957) states that the curriculum is the learning experience which is planned and directed by the school to attain its educational goal.For the purpose of this study, curriculum stands for school level curriculum prepared by Curriculum Development Centre of Nepal.

Curriculum is a crucial part in achieving national goal of education. Curriculums are aligned with national priorities and contribute to the achievement of development goals (CDC, 2007) which is defined as planned, progressive, purposeful, and systematic process in order to create positive improvements in the educational system of the country. In context of Nepal, different stakeholders participate in curriculum development process such as teachers, principals, parents, education experts, government/non-government institutions, and community members. They are involved in discussion after developing certain objectives by the experts. However, all of the above mentioned stakeholders do not participate equally in each stage of curriculum development process i.e. from need assessment to finalization. Curriculum experts have the leading role in consulting with all stakeholders and take the final decision. Though the curriculum is often claimed to be created from participatory approach, one surely can find some loop-holes. For example, there are contents which have no application in student's daily life. There are other issues in focus of curriculum, involvement of stakeholders, approaches to adopt and its assessment techniques.

This study focuses on the role of teachers and experts in curriculum development process. Here, teachers refer to those people who are directly involved in teaching learning process, and experts refers to those people who are specialists in subject matter and curriculum development process but are not directly involved in teaching learning process in school.

While developing a curriculum, developers need 
to consider about the different foundations of the curriculum such as philosophical, cultural, sociological, environmental, economical, and social (CDC, 2007). To address all these foundations, curriculum development process should be participatory and should involve teachers, experts and other stakeholders (CDC, 2012). More importantly the role of teachers and experts is crucial in incorporating these foundations in curriculum to make it effective and efficient. The school curriculum developers need to look at the learner's developmental stage, learning capacity and maturity, for which the role of teacher could not be ignored.

National curriculum of Nepal is finally approved by National Curriculum Development and Assessment Council (NCDAC) chaired by the Minister of Education who approves all curricula and guides the detailed developmental work by setting operational and administrative policy. After that, the council initially intervene the curriculum in selected schools through a pilot project. Once it gets success, the curriculum will be finalized with relevant textbook and curriculum (CDC, 2012). On the contrary, teacher has greater role and influence upon addressing the needs of the students and community at large, and thus they are the direct agent in order to deal with curriculum activities. Sitting on the top of policy making, the curriculum developed by experts may not address the major issues like student and teachers' abilities, access, need, ownership, and usefulness etc. Hence, teachers' involvement and participation are equally important not only in commenting final document but also in each steps of curriculum development.

A strong curriculum must reflect the range of interests, prior knowledge, learning styles, teacher-student-parent relations and the capabilities of the students. Such curriculum only gives results in developing effective skill based and competency based curriculum which could more readily engage the students from all aspects considering their diverse background such as geography, culture, language, contexts etc. On this backdrop, this study aims to explore what roles teachers can perform and how their roles are acknowledged in the school curriculum development. My objective is to find the role of teachers in curriculum development and know teachers roles are acknowledged in curriculum development or not.

\section{Theoretical Perspectives}

Researchers used "Habermas three interest theory" which emphasized interest of the curriculum development technical, practical and emancipatory. These interests constitute three types of science by which knowledge is generated and organized within our society (Grundy, 1987). Technical interest says that curriculum is technical and it requires greater role of the experts in curriculum development. The practical interest emphasizes the role of teachers, students and experts. In addition, emancipatory interest focus more on the role of teachers and students rather experts.

For this study, I have used curriculum theory and decision making theory to understand and interpret the collected information by considering participatory approach. Curriculum theory and gender theories were used accordingly to the situation. Decision making is an important component of curriculum development activities. As per the participation approach and gender theories, participation in decision making improves productivity and develops the ownership. It is a general pattern of action found in the rational activities of all functional and tasks of curriculum development (Hoy \& Miskel, 2001).

Researchers have also taken the help from hermeneutics to interpret this kind of study. Hermeneutics is the art of interpretations which reads the situation or phenomena. Through the foregrounds interpretations, it attempts to dig out productive questions and knowledge. There are not constructed set of fixed and rigid guidelines for a valid interpretation. In addition, this paper also wants to interpret from students/ teacher's unique perspective according to the time and contexts. Hermeneutics focuses on dialogue between teacher and learner, problem-solving skills and creates knowledge through interaction. This theory visualizes the curriculum as a process because it wanted to draw meaning from different interpretations with learners' core values. Hermeneutics says that interpretation is different from person to person.

\section{Methodology}

The methodology is used to gather data on issues associated with the teachers and experts'participation and their role in curriculum development as well as its process.

My guiding worldviews are based on social constructivist ontological position, and to some extent guided by participatory and advocacy perspectives. The study has then adopted a qualitative approach which helped to scrutinize the ideas, experiences, opinions, practices, contribution and attitudes of the study participants in relation to the practice in curriculum development process (Mason, 2002). This study has followed the narrative inquiry as the strategy of inquiry.I have chosen this strategy of inquiry to address problems of my research area. This method helped me to explore in what ways the stakeholders' practices and experiences influence the teachers' participation in the curriculum development process. This study used purposive sampling while choosing the research participants. I reached the stage of being overwhelmed with field notes, stories on the way to generating information from nine participants to satisfy the study questions as I have mentioned. Additionally, there were at least three number formal and varies in other number of informal discussions with each participants during by prolonged engagement. In-depth interview is the key tool for collection of primary information and literatures are secondary tools. Altogether eleven teachers and experts participated in the study. My participants were the representatives from secondary schools' and Curriculum DevelopmentCenter (CDC) and textbook preparing authority of school education. I selected 
participants who could provide me rich information relevant to my research question. All teacher participants were experienced in teaching learning process and curriculum experts were already involved in curriculum development process, those were asked to share their own contribution and experiences with respect to their participation in curriculum development in Nepal. While doing this, I assumed that they possessed specific views, experiences, ideas and understanding in relation to participation and contribution towards curriculum development.

Data were analyzed and interpreted narratively with description. I interviewed participants and recorded the information using tape recorder. I developed my personal reflection in writing after each interview. The interviews were accomplished in at least three to five rounds with each participant. The information gathered from the interview were transcribed and translated for further analysis. The interpretation and meaning making of the field information was based on the interpretive and critical paradigms with consideration of relevant theories, approaches and other relevant literatures. This study has taken care about consent and ethical issues from participants.

\section{Teacher as a change agent}

The term 'change' refers to transformation of one state of behaviour, attitudes, actions, situations or practices into another. Change acceptances and coping with change are the most critical aspects of effective curriculum developer. Change is the coping process of moving, converting, and transforming from the present status/situation to a desired status/situation that individuals, groups and organizations undertake response to dynamic internal and external factors that alters current situation/status (Singh, 2009). Changes can be done in each part of the curriculum development such as approaches, model, process, value, norms, premises, role and functions, context, implementation process, strategies etc., from existing condition to better, improved, goal- oriented and desired condition. School is an implementing institution to accomplish the goal of nation through the education and knowledge. It also needs to change according to the pace of time. In this context, here is the big questions that whose role is crucial in developing effective and need based curriculum according to the Nepalese contexts.

In addition, in the era of globalization, curriculum should be prepared in such a way that the students need to compete both nationally and internationally. Curriculum development can be challenging, therefore the involvement of all stakeholders, especially individuals who are directly involved in student instruction, are a vital piece in successful curriculum development and revision (Johnson, 2001). Therefore, teacher is a person who consciously and deliberately organizes systematic instructions for learners/students. While taking an interview one of the teachers said that they know the type of students/pupils that they deal with, so teachers know how certain subjects can be understood better than the ones that are copied elsewhere. They further claimed that only technical level of knowledge is insufficient for today's learners. Learners' demand are higher than technical and practical level, they demand for emancipatory level as suggested by third interest of Habermas as emancipation. Most of the teacher participants agreed that experts have to play major role in technical perspectives of the curriculum and teacher can give practical experience and social need clearly. As we know teacher need to create lesson plans and syllabi within the framework of the given curriculum since the teacher's responsibilities are to implement the curriculum to meet student needs (Carl, 2009). One of the participants said that teacher imparts knowledge to others as well as help to change the national goal into reality through teaching learning activities. Effective teaching learning happens with the proper implementation plan incorporating learnings of teachers in curriculum development. Hence, teacher involvement is important for successful and meaningful curriculum development to achieve national goals.

Teachers shared their views that the person who doesn't have any knowledge about teaching learning process in real field are acting as a curriculum experts and those experts own greater influential role than teachers. As per the perceptions of teachers they thought experts works without ground reality. Many teachers during the interview expressed that if they suggest for changing the content looking over the one context, theexperts change it to some extent, but they don't do proper consultation with sufficient numbers of teachers who have real ground experiences. This assertion entails that the teacher who is no longer practising may not be in the position to have the actual feel of what takes place in the classroom. Similar study done by Carl (2005) focused the role of teachers in curriculum development. Carl also attempted to contribute to the discourse by focusing on what is meant by teacher involvement in brief, the possible viewpoints regarding this concept, and the real nature and extent of possible involvement within a specific South African context which is similar finding of this study.This asserts that experts are selected on the basis of their educational level without having field level experiences. Habermas (1971) points out the major weaknesses of viewing the technical interest as the only path to knowledge. One the contrary, one of the expert participants said that they agree that teachers have greater understanding on societal need but not able to reflect that in practice to make emancipation(Marsh, 2009). Therefore,teachers' role is emphasized in curriculum to meet the need of the society. Those changes can be faced by teachers in implementation of curriculum which guides teachers to develop new methods, approaches, strategies to cope with.Teachers need to become levers for change in the curricula. Change cannot be successful if the teacher focuses on the classroom only (Carl, 2005).Because of these reason teachers' role needs to be emphasized in curriculum development process but we cannot totally deny the role of experts. The main point here is that if the teachers are not familiar with the direct goal of curriculum, then only limited outcomes can be expected from them.

Preedy et al. (1997) mentions that curriculum and 
textbooks play major role to change the society from its traditional state to the modern one. In particular, school level curriculum and textbook play an important role in education sector. Metre (2009) outlines that the change can happen according to the pace of time and need of the people which are further driven by economic, social and environmental factors. Change is only one of the forces competing for the teachers' attention and usually not the most compelling one (Oktober, 2009, p. 10). One of the teacher participants said that curriculum developers are selected on the basis of their own interest who are mere listener/follower of the member secretary rather than challenging them.

When I went through the meeting minutes, I found that teacher curriculum developers were absent in most of the meetings. While exploring the reasons for their absence, teachers mentioned that that was due to the inconvenient time for them and were not consulted in fixing the meeting date. This remarks asserts that the context of decision making role of teachers is already underestimated. The process of curriculum development requires teachers to act and reflect on society's needs in each stage of the development process.

This study found such ideas to be similar with Oktober (2009) who states that educational changes create new challenges and perspectives for the role of teachers.To implement curriculum in the school those are the teachers within education system who have to adopt new ideologies and implement them in their teaching, since it is the teachers who are responsible for passing on the changes through their teaching to their students (Kennedy\& Kennedy, 1996). Many studies support that life skill included curriculum is possible through participation and empowerment of teachers in curriculum development.

\section{Critical practitioner producing knowledge through curriculum}

Curriculum are representations of knowledge for teaching learning process. The process is performed by teachers. They are not only acting as teacher but also performing a role of practitioner/implementer and evaluator ofthe developed curriculum. They are playing important both in the instruction and curriculum development as per the intent of National Curriculum Framework (NCF, 2007).Nowadays, teachers are also taken as a researcher (Stenhouse, 1980 as cited by Elliot, 2005) and we should not undermine their knowledge and intellectuality.Curriculum is based upon an understanding of the knowledge, skills, attitudes and beliefs individuals need to carry out specific tasks.

Participatory curriculum development can help to gain greater responsibility and ownership which increases the motivation and commitment of everyone who participate in that process (Taylor, 2003). Participatory approach to curriculum development is necessary because it ensures effectiveness, sustainability and ownership (Hoy \&Miskel, 2001).According to the Habermas' three interest theory, if the curriculum is developed by the experts (technical curriculum), it will not allow participating teachers and students in curriculum development, rather it only emphasizes on the instruction adhered by the curriculum experts. On the other hand, practical interest guided curriculum allows students and teachers to participate and engage with the experts.Indeed, curriculum is best suited for addressing students' aspects and teachers' capabilities to implement that curriculum. Fullan (2002) observed that the teacher has to be fully involved in curriculum planning to fully understand the curriculum. As a third interest, Habermas presented as an emancipatory interest or praxis. From these interests we can see the major role of the teachers to develop practical and empowering curriculum. Professional development of teachers is as an important factor contributing to the success of curriculum development and implementation (Handler, 2010) as well as reflect future job opportunities.

Teachers expose students to use multiple perspectives and allow students to analyse critically the differences between mainstream cultural ideals and those of different cultural systems. Carl (2005) indicated that teachers were excluded in some steps of curriculum development which prevented them from incorporating their learning. In the similar context, Handler (2010) also found that there is a need for teacher involvement in the development of curriculum. Following this, the present study argues for the unavoidable role of teachers which should be emphasised in curriculum development.

Teachers guide students to reflect on their own ethnic identities and facilitate them in honouring other cultures and developing positive cross-cultural relationships. This has been truly reflected in the field study of this research. To illustrate further,one teacher emphasized and said "I think teachers as they are teaching they know which areas are supposed to be.... you know the way the curriculum is supposed to be tenured .....as they teach, they know which areas are supposed to be taught first and last but you find if they are not there, the people that will come up with that document, you will find that they will mix up things". Teachers can contribute by collaboratively and effectively working with curriculum development teams and specialists to arrange and compose material, textbooks, and content. Classroom activities should enhance students' abilities to identify stereotypes and prejudices and also teach students how to avoid perpetuating racism (Gay, 2002). Those experiences of teachers enhance their knowledge to develop culturally responsive curriculum which treat all students culture equally. Furthermore, teachers must make their teaching well suited to the socio-cultural contexts and frames of reference of ethnically diverse students. In curriculum development process, those teachers need to involve who have all above mention qualities to enhance students learning as well as reflect societal need.

\section{Rationale for teacher involvement in curriculum development}

In the case of Nepalese curriculum, the curriculum is developed by the CDC including different stakeholders 
such as teachers, experts, parents, and governmental/nongovernmental organization's representatives. Participatory approach, integrated approach, content approach, process approach, product approach, Tyler model, Taba model, instructional model, etc., can be taken as examples of approaches for curriculum development (OECD, 2012).

For developing curriculum, curriculum draft taskforce will be developed which includes subject specialists, curriculum specialists, educationist, and subject teachers. In each committee teachers are involved. While discussing with teachers they expressed that if they got the opportunities to participate the process of curriculum development, they could act and reflect the society's needs. Nevertheless,this process, where teachers are requested to follow, is unclear sometimes. But they have the limited opportunities to take decisions about curriculum. Teachers only can understand the psychology of the learner. Teachers are aware about the teaching methods and teaching strategies. Teachers also play the role as evaluator for the assessment of learning outcomes. Most of the research participants in this study expressed that they (teacher) should have a mandatory presence to involve in each events/meetings of curriculum development and decision making. It asserts that still teachers are unable to participate in each stages of curriculum development. Because teachers are well known about the availability of resources, developmental readiness or developmental appropriateness of the students and teachers themselves, students' psychology, time schedule etc.Giroux (2011) suggested that teachers can play a role as 'public intellectuals', engaging in the debates regarding more equitable and democratic societies. Yet, researcher have not ignored the issues of teachers' monopoly. We need to develop monitoring mechanisms to control their monopoly. Such a mechanism, however, need to promote the teachersinvolvement rather hinders their active participation.

With the essence of three interest theory, teacher participants also clearly express their opinion that they do have a role to play at curriculum levels outside the classroom to incorporate the practical knowledge but their voices "are not listened to" as per expected context. Knowledge is generated and the idea that each individual has his/her own cognitive interest was important for curriculum development and design. Experts agreed on that teachers' involvement is essential not only for the sake of institutional and curriculum development in schools and the country's curriculum, but also for nurturing the personal and professional growth.Unlike the expert's point of view, one of the teacher participants expressed that they can filter curriculum as per the students' level and their necessity which also develops ownership among the teachers through a participatory approach. Teachers' participation can therefore bring positive results. Several studies in different contexts show that teachers want to be involved in curriculum development (Bourn 2015). Most of the researchers such as Fullan and Hargreaves (1992), Carl (1994), Kirk and Macdonald (2001), Fullan (2001) and Carl (2005) found that the positive changes in curriculum and attainment of national goals set by curriculum with active involvement of the teachers than experts. Ultimately effective curriculum development process can enhance the students' learning.

\section{Conclusion}

Experts are taking more responsibilities and authorities in curriculum development in Nepal. However, other important actors the teachers' role is minimized in all steps of curriculum development process - planning, development, implementation and feedback. Curriculum development should be viewed as a process by which meeting the social needs, improving the student learning outcomes and promoting the knowledge at large. However, the process of curriculum development may be affected by various critical factors, including un-clarity in curriculum development policies, dominance of top down approaches and power holding attitude of experts.Current role of teachers as reviewers of final document prepared by experts has the limited scope of incorporation of their creativity and practical experience. As a result, secondary level school curriculum looks like opposing practical and emancipatory approaches of curriculum development. In addition, experts perceive teachers as knowledge imparting actors only. This not only undermines the role of teachers but misses opportunities to capture their real life experiences in curriculum making and delivery. Teachers claimed that they could play important roles during the curriculum development process and would guarantee effective curriculum implementation if they are allowewd (Mason, 2009). Teachers' real-life experience related to talent and capacity of students and respective capacity of teachers supports in best use of available resources, preparation of doable teaching methods and developing flexible assessment system.

Thus, I argue for the recognition of teachers'role in curriculum development to make it more useful and practical that addresses the societalneeds at secondary level of school education in Nepal.

\section{References}

Brown, K. W., Ryan, R. M., \& Creswell, J. D. (2007). Mindfulness: Theoretical foundations and evidence for its salutary effects. Psychological Inquiry, 18(4), 211237.

Bourn, D. (2015). Teachers as agents of social change. International Journal of Development Education and Global Learning 7 (3), 63-77

Carl, A. (2009). Teacher empowerment through curriculum development theory into practice. Juta\& Company Ltd. E

Carl, A. (2005). The "voice of the teacher" in curriculum development: a voice crying in the wilderness? South African Journal of Education Vol. 25(4)223-228

Connelly, F. M., Clandinin, D. J. (1990). Stories of experience and narrative inquiry. Journal of Educational Researcher, 19(5), 2-14.

Curriculum Development Center (2007). National 
curriculum Framework, 2007. Bhaktapur: Authors.

Curriculum Development Center (2012). Curriculum and textbook development guidelines, 2068. Bhaktapur: Authors.

De Coninck, C. (2008). Core affairs: Flanders, Belgium: case studies basic education in Europe. Retrieved from: Webversie core_affairs_LR_Belgi_def.pdf

Elliott, J. (2006). The Teacher's Role in Curriculum Development: an unresolved issue in English attempts at curriculum reform. Curriculum Studies, 2:1, 43-69. Retrieved from http://dx.doi. org/10.1080/0965975940020103

Fullan, M. (2001). The new meaning of educational change. New York: Teachers' College Press.

Fullan, M. (2002). The Change Leader. Educational Leadership, 59(8): 16-21

Fullan, M. \& Hargreaves, A. (1992). Teacher development and educational change. London: The Falmer Press.

Gay, G. (2002). Preparing for Culturally Responsive Teaching. Journal of Teacher Education Vol. 53, No. 2, 106-116.Retrieved from http://www.sagepub.com/ eis/Gay.pdf

Giroux, H. (2011). On Critical Pedagogy. New York: Bloomsbury Publishing.

Grundy, S. (1987). Curriculum: Product or praxis. RoutledgeFalmer:London

Habermas, J. (1971). Knowledge and human interests (J. J. Shapiro, Trans.). Boston: Beacon Press.

Handler, B. (2010). Teacher as Curriculum Leader: A Consideration of the Appropriateness of that Role Assignment to Classroom-Based Practitioners. International Journal of Teacher Leadership vol.3 no.3 ISSN 1934-9726. Retrieved from www.csupomnoa. edu/ijtl

Hoy, W., \&Miskel, C. (2001). Educational administration: Theory, research and practice (6thed.). New York, NY: McGraw-Hill.

Johnson, J. A. (2001). Curriculum revision that works. In principles of effective change.

Kennedy, C. and Kennedy, J. (1996). Teacher attitudes and change Implementation. Elsevier Science Ltd.

Kirk, D. \& Macdonald, D. (2001). Teacher voice and ownership of curriculum change. Journal of Curriculum Studies,33 pp.551-567.

Lunenburg, F. C. \& Ornstein, A. C. (2004). Educational Administration: Concepts and Practices (4thed.). Belmont, CA: Wadsworth/Thompson Learning.

Marsh, C. (2009). Key concepts of understanding curriculum. London: Rutledge / Taylor \& Francis Group.

Mason, J. (2002). Researching your own practice: The Discipline of Noticing. Oxon: Routledge.

Metre, C. (2009). Deriving value from change management (Unpublished Doctoral dissertation). Retrieved from http://repository.upenn.edu/od_theses_msod/28.

Miles, H.B., and Huberman, A.M. (1994). Qualitative Data Analysis. Sage Publication, Thousand Oaks:California.

Oktober, S. G. (2009). The principal as a curriculum leader during a time of educational change. South Africa:
Stellenbosch University. Retrieved from http://www. scholar.sun.ac.za

Organization for Economic Co-operation and Development. (OECD, 2012). Education at a glance 2012: OECD Indicators. OECD Publishing. Retrieved from https://www.oecd.org/edu/EAG\%20 2012_e-book_EN_200912.pdf

Preedy. $\bar{M}$, Glatter. $\bar{R}$ \&Levapiü.R (1997). Educational Management. Strategy, Quality and Resources. Open University Press.

Singh, H. (2003). Building effective blended learning programs. Issue of Educational Technology, 43 (6), 5154

Taylor, P. (2003).How to Design a Training Course: A Guide to Participatory Curriculum Development. London: Continuum.

Tyler, R. W. (1957). The curriculum then and now. In Proceedings of the 1956 Invitational Conference on Testing Problems. Princeton, NJ: Educational Testing Service.

Rimal, Kalpana is an independent researcher. She holds MPhil Degree in Education from Kathmandu University. She has interest in educational research with focus on gender issues in education. Professionally, she is working with non-government organization - OLE Nepal, in a capacity of Senior Officer.

Email: kalpana.rimal@olenepal.org 